\title{
GPS Accuracy for Tree Scouting and Other Horticultural Uses 1
}

Reza Ehsani, Sherrie Buchanon, and Masoud Salyani²

\section{Introduction}

After the outbreak of citrus greening disease (HLB), tree scouting has become a normal practice in Florida. In most cases, growers are using global positioning systems (GPS) to map the infected trees for subsequent tree removal and recordkeeping purposes. While GPS-located maps are somewhat accurate, there are instances in which the GPS location could be significantly inaccurate. This could then cause problems locating the infected trees or using the location data for future use. Figure 1 shows an example of a GPS location map of HLB-infected trees (red triangles) that are overlaid on an aerial image. As shown, it is impossible to determine from some data points (circled in blue) the correct HLBinfected tree. This article provides some simple explanations of the causes of GPS error and the level of accuracy that can be expected from different classes of GPS receivers.

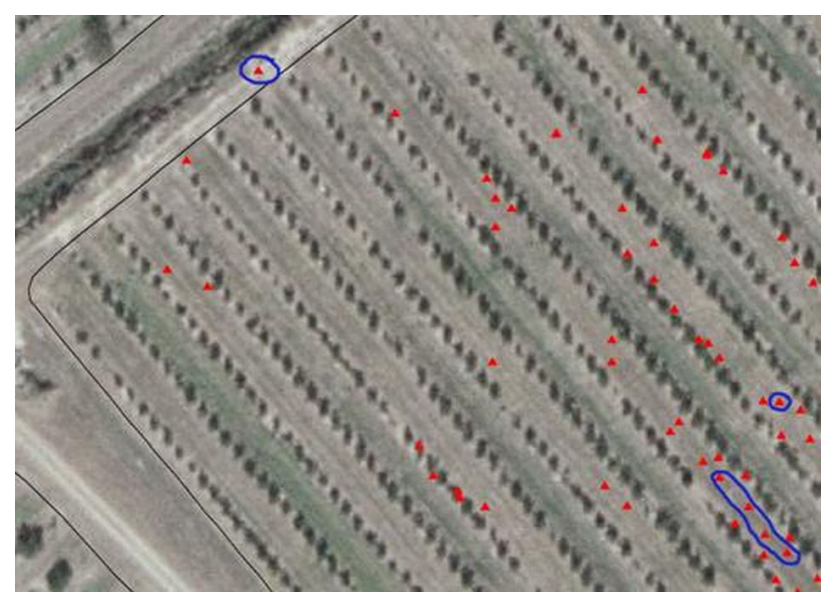

Figure 1. A GPS location map of HLB-infected trees overlaid on an aerial image.

\section{How GPS works}

The GPS receiver, like a radio, receives signals from different GPS satellites. Every time the GPS receiver receives a signal, it calculates its distance from that satellite. When there are at least four satellites in view, the GPS receiver can calculate its exact location (i.e. latitude, longitude and altitude) using triangulation. GPS constellation and the satellite orbits are designed in such a way that for any

1. This document is AE438, one of a series of the Agricultural and Biological Engineering Department, Florida Cooperative Extension Service, Institute of Food and Agricultural Sciences, University of Florida. Original publication date January 2009. Revised October 2009. Visit the EDIS Web Site at http://edis.ifas.ufl.edu.

2. Reza Ehsani, assistant professor; Sherrie Buchanon, senior engineering technician; Masoud Salyani, professor; Department of Agricultural and Biological Engineering, Citrus Research and Education Center (REC)-Lake Alfred; Florida Cooperative Extension Service, Institute of Food and Agricultural Sciences, University of Florida, Gainesville, FL 32611.

The Institute of Food and Agricultural Sciences (IFAS) is an Equal Opportunity Institution authorized to provide research, educational information and other services only to individuals and institutions that function with non-discrimination with respect to race, creed, color, religion, age, disability, sex, sexual orientation, marital status, national origin, political opinions or affiliations. U.S. Department of Agriculture, Cooperative Extension Service, University of Florida, IFAS, Florida A. \& M. University Cooperative Extension Program, and Boards of County Commissioners Cooperating. 0 LCH ) HWH\&KDQF प,QMAP $\square$ ' HDQ 
point on earth at any particular time there are at least four satellites in view at ground level. In most cases, there are 5-9 satellites in view. In the near future, this number will be increased because European countries are putting a similar system, called Galileo, into orbit. The Galileo system will use the same signal structure as GPS satellites which means that in the future, there will be more satellites in view in the sky. With more satellites in view, signal accuracy is expected to be improved, which should benefit GPS orchard applications.

\section{Sources of Error}

There are many factors that affect GPS accuracy. Some of them are caused by the slight deviation of GPS satellites from their orbit or by the atmospheric and environmental conditions through which the signals must travel to reach the GPS receiver. The geometry of satellite position in the sky, i.e., where satellites are located at any moment, can also affect GPS accuracy. Let's assume there are five satellites in view and they are evenly distributed in the sky. This configuration of satellites could produce much smaller error compared to a situation in which five satellites are clumped near each other in one region of the sky. The geometric orientation of the GPS satellites is referred to as "dilution of precision" (DOP) and can influence GPS error with changes in time and location. Some GPS receivers can show the DOP value. A DOP value between 2 and 4 is considered good and anything above 8 is considered to be poor and could cause high GPS error.

\section{Differential Correction Signal}

To reduce error, GPS receivers can acquire other radio frequency signals called "differential correction" signals. There are several types of differential correction signals available today; some of them are free while others must be obtained by paying a subscription fee. The two most common sources of free differential signals are "wide area augmentation system" (WAAS) and "coast guard beacon" (CGB) signals. Almost all GPS receivers available on the market today have the capability of using the WAAS signal. The CGB radio frequencies are susceptible to noise and interference. To use the CGB signal, the receiver needs additional hardware; therefore, these receivers are usually costlier and a little larger in size. Nowadays, most new receivers that can receive the CGB signal can also receive the WAAS signal. The advantage of these receivers is that if they lose one correction signal, they can automatically switch to the other correction signal to maintain higher GPS accuracy and resolution.

\section{Accuracy Classifications}

GPS receivers are typically designed for different purposes, which usually corresponds to the level of accuracy they possess. The level of accuracy required depends on the user and application and can be expressed in terms of relative and absolute accuracy. Relative accuracy is a measure of short-term repeatability of a GPS receiver. Absolute accuracy determines how close the reported location is to its true location. A good GPS receiver has a good absolute and relative accuracy. Some of the lower cost receivers have good relative accuracy but only fair absolute accuracy. If you plot the data from such a receiver, you will notice that the datapoints are very good with respect to each other; however, they are shifted from their true position as illustrated in Fig. 1 .

\section{What to consider when choosing a GPS receiver for scouting}

Knowing the level of accuracy needed for a particular application is important in selecting the right GPS. A GPS user needs to understand the limitations of different types of receivers and how those limitations will affect the data collected. The currently available GPS receivers used for agricultural applications can be classified into four general categories based on their accuracy level. The accuracy levels are less than 15 feet, less than 3 feet, less than 12 inches, and less than 1 inch horizontally. The first two levels ( $<15$ feet and $<3$ feet) are primarily useful for soil sampling and scouting type applications. The remaining two levels $(<12$ inch and $<1$ inch) describe applications pertaining to vehicle guidance and surveying. Table 1 shows the price range and typical applications for these four classes of GPS receivers. The highest level of accuracy can be obtained by "Real Time Kinematic" (RTK) GPS. This type of GPS works on a different principle 
compared to regular DGPS receivers. RTK GPS are usually very expensive and mainly used for surveying. However, recently they have become increasingly utilized for certain agricultural applications such as auto-steering guidance.

\section{Things to consider when purchasing a GPS Receiver}

-When comparing GPS receivers, make sure the units of accuracy are comparable. A GPS with 6 ft RMS position accuracy has the same accuracy level as a GPS with $12 \mathrm{ft}$ 2DRMS.

- In general, if you are close to a Coast Guard Beacon signal (less than 50 miles) you can expect to get less errors compared to WAAS. However, in central Florida, errors from WAAS and Coast Guard Beacon signals are nearly equivalent.

- Some low-cost GPS receivers only use 6-decimal places to report coordinate information compared to the 8-decimal places that higher-end GPS receivers provide. This small fractional difference can translate to large differences in GPS receiver accuracy.

- Tree canopy can have a mixed effect on GPS accuracy depending on the orientation, tree size, and density. In general, for a very tall and dense canopy, the antenna mounting height should be raised to a level near the top of the canopy to avoid signal blockage.

- Keep in mind that accuracy performance of GPS is good $95 \%$ of the time but there is still a $5 \%$ chance that you may acquire a point outside the machines accuracy range.

- Before purchasing a GPS, first decide what level of accuracy you need. Keep in mind that you generally pay more to achieve higher accuracy.

- Most commonly available GPS receivers have 12 channels which means they can track up to 12 satellites at the same time. Since, there are going to be more satellites in view in the sky at any given time, in the near future it would be a good idea to purchase a GPS with greater than 12 channels. There are some new GPS systems that have 20 channels.

- If you need to go back to a specific field location year after year, you should consider RTK because the position of a recorded point with a regular differential global positioning system (DGPS) receiver has the tendency to shift with time, but not with RTK.

- If you have already purchased a GPS that has a low level of accuracy, make sure to use other means of marking the infected tree (paint, etc.) and don't just trust the GPS location information.

\section{Useful information on Specific GPS Receiver specifications}

Trimble Ag 106 - In differential GPS mode using WAAS DGPS corrections, the AgGPS 106 outputs positions with 1-3 m (3-10 ft) accuracy (static HRMS). Connects to laptop/PDA using a serial connection.

Trimble Ag 332 - It has $+/-2.5 \mathrm{~cm}$ (1 in) pass-to-pass and year-to-year repeatable accuracy using RTK, +/- 5-10 cm (5 - 10 in) pass-to-pass accuracy using OmniSTAR HP, $+/-7.5-12.5 \mathrm{~cm}$ (3 -5 in) pass-to-pass accuracy using OmniSTAR XP, $+/-15-20 \mathrm{~cm}(6-8$ in) pass-to-pass accuracy using WAAS, EGNOS, beacon, or OmniSTAR VBS.

Trimble Ag 214 - RTK - $1 \mathrm{~cm}(0.4$ in $)+2$ parts per million (ppm) baseline distance horizontal $2 \mathrm{~cm}$ $(0.79$ in $)+2 \mathrm{ppm}$ baseline distance vertical .

Trimble Ag 252 - Horizontal RTK positioning accuracy $2.5 \mathrm{~cm}(0.98 \mathrm{in})+2 \mathrm{ppm}, 2$ sigma; vertical RTK positioning accuracy $3.7 \mathrm{~cm}(1.5 \mathrm{in})+2 \mathrm{ppm}, 2$ sigma Sub-meter differential accuracy (RMS), assuming at least five satellites and a PDOP of less than four.

Garmin eTrex Legend - Position $<15 \mathrm{~m}(<50$ $\mathrm{ft}), 95 \%$ typical, Velocity $0.05 \mathrm{~m} / \mathrm{s}$ steady state.

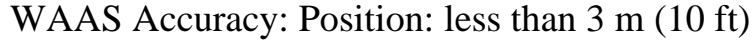
RMS Velocity: 0.1 knot RMS steady state. 
Garmin GPS 72 - GPS Accuracy: Position < 15 $\mathrm{m}$ (<50 ft), $95 \%$ typical, Velocity: $0.05 \mathrm{~m} / \mathrm{s}$ steady state.

Garmin GPS 17 - Position: < 15 m, 95\% typical, Velocity: 0.1 knot RMS steady state, DGPS (USCG) accuracy: Position: 3-5 m (9.84 - $16.4 \mathrm{ft})$, 95\% typical, Velocity: 0.1 knot RMS steady state, DGPS (WAAS) accuracy: Position: $<3 \mathrm{~m}(<9.84$ ft), $95 \%$ typical, .1 knot RMS steady state.

Garmin 18 GPS - In differential GPS mode using WAAS DGPS corrections, the Garmin 18 GPS outputs positions with 1-3 m (3-10 ft) accuracy (static HRMS). Connects to laptop/PDA using either USB or Serial connection.

TopCon GMS-2 - Handheld, $3 \mathrm{~mm}(0.3$ in $)+0.8$ ppm horizontal, $4 \mathrm{~mm}(0.4 \mathrm{in})+1.0 \mathrm{ppm}$ vertical (static), 50cm (1.64 ft) HRMS Post Processing, $50 \mathrm{~cm}$ (1.64 ft) HRMS Real time (DGPS), 10mm (4 in) + $1 \mathrm{ppm}$ horizontal, $15 \mathrm{~mm}$ (5.9 in) $+1 \mathrm{ppm}$ vertical (PP Kinematic), 50 channels cold tracking - <30 seconds, warm tracking - <10 seconds, GPS/GLONASS L1 C/A Code \& Carrier WAAS/EGNOS/MSAS.

TopCon GR3 - Static 3mm (0.3 in) $+.5 \mathrm{ppm}$ horizontal, $5 \mathrm{~mm}(0.5 \mathrm{in})+0.5 \mathrm{ppm}$ vertical, RTK/Kinematic $10 \mathrm{~mm}$ (1 in) + 1 ppm horizontal, $15 \mathrm{~mm}(1.5 \mathrm{in})+1 \mathrm{ppm}$ vertical, DGPS $>0.3 \mathrm{~m}(>0.8$ ft) Post Processing, $<0.50 \mathrm{~m}(<1.6 \mathrm{ft})$ Real time.

Magellan MobileMapper CE - Real-time accuracy - sub-meter, Post-mission accuracy - $<30$ $\mathrm{cm}(6.4 \mathrm{ft})$, Bluetooth, USB host and slave, RS232, Waterproof to one meter depth for 30 minutes.

Magellan MobileMapper Pro - Real-time accuracy - 2-3 m (6.6 - $9.9 \mathrm{ft})$, Post-mission accuracy - Sub-meter, Connector - Serial data cable, Waterproof to one meter depth for 30 minutes.

Lowrance iFinder Expedition C - WAAS and GPS Accuracy to $7 \mathrm{~m}$ (23 ft), Waterproof to IPX7 standard, Built-in microphone for recording voice notes to waypoints, Built in Compass and barometric altimeter with weather predictions.

AgLeader GPS 5100 - Differential position accuracy - less than one $\mathrm{m}(3.8 \mathrm{ft})$ horizontal is all of the following criteria are met: At least five satellites, PDOP <4, RTCM SC-104 corrections, Standard format broadcast from a Trimble MS750, AgGPS 214, or equivalent reference station. RTK position accuracy $2.5 \mathrm{~cm}(0.98 \mathrm{in})+2 \mathrm{ppm}, 2$ sigma, and vertical $3.7 \mathrm{~cm}$ (8.3 in) +2 ppm, 2 sigma.

AgLeader GPS 1100 - Accuracy with WAAS/EGNOS Diff: $2 \mathrm{~m}(6.6 \mathrm{ft}) \mathrm{RMS}$, Accuracy GPS only: 4m (13.1 ft) RMS, Output NMEA-0183.

Trimble Juno - Handheld GPS with 2 to $5 \mathrm{~m}$ $(6.6-16.4 \mathrm{ft})$ accuracy WAAS.

Raven Phoenix 200 smart antenna - up to 10 Hz, WAAS, 2 - 5 m (6.6 - $16.4 \mathrm{ft})$ accuracy.

Raven Invicta 210 - up to $10 \mathrm{~Hz}$, WAAS and Beacon Corrected.

Raven Invicta 100 - 2 m (6.6 ft) RMS, WAAS.

Raven Invicta 115 - Smart Antenna no separate receiver box, Differential Correction Option: WAAS, 10 Channel, $5 \mathrm{~Hz}$ update rate, 2 serial port Accuracy $<1 \mathrm{~m}$ (3.3 ft) RMS.

Raven Invicta 310 - Integrated high performance GPS receiver with WAAS, radiobeacon and L-Band satellite differential.

Raven Invicta 410 - Decimeter differential GPS accuracy, Data rate up to $20 \mathrm{~Hz}, \mathrm{~L} 1 / \mathrm{L} 2$ capable, WAAS, CDGPS, OmniStar, EGNOS and MSAS; Decimeter accuracy: OmniSTAR HP \& Raven Enhancer.

Raven Phoenix 300 smart antenna - up to 10 Hz, WAAS, Canadian WAAS, and OmniStar VBS, Sub meter accuracy and upgradeable to decimeter accuracy.

TeeJet RX370p - up to $10 \mathrm{~Hz}$, WAAS, EGNOS and e-diff sub meter accuracy.

TeeJet RX500 - user configurable up to $20 \mathrm{~Hz}$, $5-10 \mathrm{~cm}(2-4 \mathrm{in})$ accuracy.

TeeJet RX410p - WAAS, Omnistar, beacon and e-diff sub-meter accuracy, up to $10 \mathrm{~Hz}$ update rate. 
HP iPaq rx5915 - Handheld GPS WAAS, WLAN $(802.11 \mathrm{~b} / \mathrm{g})$, Bluetooth 2.0 Enhanced Data Rate, Samsung SC32442 400MHz Processor, Integrated SiRFstarIII GSC3F GPS.

Mio DigiWalker P550 - Handheld GPS WAAS, 20 channel SiRFStarIII GSC3F GPS, Samsung 2440 $400 \mathrm{Mhz}$ processor.

\section{Manufacturers}

Ag Leader Technology, Inc. -Tel:

(515)232-5363 website: www.agleader.com

Garmin International Inc. -Tel: (913)397-8200

website: www.garmin.com

Lowrance Electronics, Inc. -Tel:

1-800-324-1356 website: www.lowrance.com

Magellan Navigation, Inc. -Tel:

1-800-707-9971 website: www.magellangps.com

Topcon America Corp. -Tel: 1-800-223-1130

website: www.topconpa.com

Trimble Navigation Limited -Tel:

1-800-874-6253 website: www.trimble.com

Teejet - Tel: 630-665-5000 website:

www.teejet.com

Raven -Tel: (800)243-5435 website:

www.ravenprecision.com/

HP -Tel: (800)474-6836 website: www.hp.com

Mio - Tel: (866)-646-4477 website:

www.mio-tech.com,

\section{Useful links}

GPS Tutorial -

http://www.trimble.com/gps/index.shtml

GPS Overview -

http://www.colorado.edu/geography/gcraft/notes/gps/ gps_f.html

GPS Tutorial http://facility.unavco.org/project_support/campaign/ training/jpstutorial.pdf 
Table 1. Comparison of four classes of GPS receivers

\begin{tabular}{|c|c|c|c|c|c|}
\hline \multirow[b]{2}{*}{$\begin{array}{l}\text { Accuracy } \\
\text { Level }\end{array}$} & \multicolumn{2}{|c|}{ Free DGPS Based } & \multirow{2}{*}{$\begin{array}{l}\text { Subscription } \\
10-12 \mathrm{in} \\
1-1.2 \mathrm{~cm}\end{array}$} & \multicolumn{2}{|c|}{ Real Time Kinematic (RTK) } \\
\hline & $\begin{array}{l}5-15 \mathrm{ft} \\
1.52-4.57 \mathrm{~m}\end{array}$ & $\begin{array}{l}2-3 \mathrm{ft} \\
.61-.91 \mathrm{~m}\end{array}$ & & $\begin{array}{l}\text { Local Base } \\
1-2 \text { in } \\
10-20 \mathrm{~mm}\end{array}$ & $\begin{array}{l}\text { CORS } \\
1-2 \text { in } \\
10-20 \mathrm{~mm}\end{array}$ \\
\hline Price & $\$ 100-\$ 800$ & $\$ 800-\$ 2500$ & $\$ 2500-\$ 6000$ & $\begin{array}{l}\text { Base: } \$ 16 k- \\
\text { \$25k Rover: } \\
\$ 16 k-\$ 20 k\end{array}$ & $\begin{array}{l}\text { Base: } \sim \$ 30 \mathrm{k} \\
\text { Rover: } \$ 6 \mathrm{k}- \\
\text { \$12k Yearly } \\
\text { Fees: } \$ 1 \mathrm{k}\end{array}$ \\
\hline $\begin{array}{l}\text { Differential } \\
\text { Correction } \\
\text { Source } \\
\end{array}$ & WAAS & $\begin{array}{l}\text { Dual Frequency } \\
\text { StarFire } 1\end{array}$ & $\begin{array}{l}\text { OmniStar XP \& HP } \\
\text { StarFire } 2\end{array}$ & RTK Base & $\begin{array}{l}\text { Local Network of } \\
\text { RTK Base } \\
\text { Stations }\end{array}$ \\
\hline $\begin{array}{l}\text { Static } \\
\text { Accuracy }\end{array}$ & 3 - 5 Feet & 12 - 36 Inches & 8 - 12 Inches & $\begin{array}{l}1 \text { - } 2 \text { Inches } \\
\text { (Determined } \\
\text { by Distance to } \\
\text { Base Station) }\end{array}$ & 1 - 10 Inches \\
\hline $\begin{array}{l}\text { Static } \\
\text { Stability }\end{array}$ & Not Stable & Fairly Stable & Stable & Very Stable & Very Stable \\
\hline $\begin{array}{l}\text { Year to Year } \\
\text { Repeatability }\end{array}$ & None & None & Marginal $~ 1$ Foot & Very Stable & Very Stable \\
\hline $\begin{array}{l}\text { Precision } \mathrm{Ag} \\
\text { Uses }\end{array}$ & $\begin{array}{l}\text { Soil } \\
\text { Sampling }\end{array}$ & $\begin{array}{l}\text { Previous + } \\
\text { Non-Critical } \\
\text { Lightbar } \\
\text { Guidance } \\
\text { (Spraying, } \\
\text { Tillage) Yield } \\
\text { Monitoring }\end{array}$ & $\begin{array}{l}\text { Previous + Critical } \\
\text { Lightbar Guidance } \\
\text { (Planting) }\end{array}$ & $\begin{array}{l}\text { Previous + } \\
\text { Autosteering } \\
\text { Cultivating }\end{array}$ & $\begin{array}{l}\text { CORS uses a } \\
\text { cellular modem } \\
\text { to transmit } \\
\text { correction } \\
\text { information. It is } \\
\text { mainly used by } \\
\text { surveyors, but is } \\
\text { gaining interest } \\
\text { in agriculture. }\end{array}$ \\
\hline
\end{tabular}


Table 2. Comparison of some commercially available GPS receivers in four accuracy classes

\begin{tabular}{|c|c|c|c|}
\hline Class I & Class II & Class III & Class IV \\
\hline $\begin{array}{l}\text { Trimble Juno } \\
\$ 650^{*}\end{array}$ & $\begin{array}{c}\text { Raven Invecta } 115 \\
\$ 1,245^{\star}\end{array}$ & $\begin{array}{c}\text { TopCon GMS-2 } \\
\$ 4,350^{*}\end{array}$ & $\begin{array}{c}\text { Trimble Ag } 214 \\
\$ 20,000-\$ 30,000^{*}\end{array}$ \\
\hline $\begin{array}{c}\text { Garmin } 18 \\
\$ 75^{\star}\end{array}$ & $\begin{array}{l}\text { TeeJet RX370p - } \\
\qquad 1,844^{*}\end{array}$ & $\begin{array}{l}\text { AgLeader GPS } 5100 \\
\$ 5,000^{\star}\end{array}$ & $\begin{array}{c}\text { Trimble Ag } 252 \\
\$ 20,000-\$ 30,000^{*}\end{array}$ \\
\hline $\begin{array}{l}\text { Garmin } 72 \\
\$ 99-\$ 200^{*}\end{array}$ & $\begin{array}{l}\text { Trimble } 106 \\
\$ 1,200^{*}\end{array}$ & $\begin{array}{c}\text { Raven Invicta } 310 \\
\$ 3,140^{*}\end{array}$ & $\begin{array}{c}\text { TopCon GR3 } \\
\$ 33,845-\$ 63,119^{*}\end{array}$ \\
\hline $\begin{array}{c}\text { Garmin } 17 \\
\$ 130^{*}\end{array}$ & $\begin{array}{l}\text { Magellan Mobile Mapper CE } \\
\qquad 1,975-\$ 2,500^{*}\end{array}$ & $\begin{array}{c}\text { Raven Invicta } 410 \\
\$ 5,750^{*}\end{array}$ & \\
\hline $\begin{array}{l}\text { Garmin e-trex legend } \\
\quad \$ 130-\$ 250^{*}\end{array}$ & $\begin{array}{l}\text { Magellan Mobile Mapper Pro } \\
\qquad \$ 1,750-\$ 2,750^{*}\end{array}$ & $\begin{array}{c}\text { Raven Phoenix } 300 \text { smart } \\
\text { antenna } \\
\$ 3,660-\$ 5,485^{\star}\end{array}$ & \\
\hline $\begin{array}{l}\text { Lowrance iFinder } \\
\text { Expedition C } \\
\$ 242-\$ 350^{*}\end{array}$ & $\begin{array}{c}\text { Raven Phoenix } 200 \text { smart } \\
\text { antenna } \\
\$ 1,465^{\star}\end{array}$ & TeeJet RX500 - $\$ 5,154^{*}$ & \\
\hline $\begin{array}{l}\text { HP iPaq rx } 5915 \\
\$ 500^{*}\end{array}$ & $\begin{array}{c}\text { Raven Invicta } 210 \\
\$ 2,005^{*}\end{array}$ & $\begin{array}{c}\text { TeeJet RX410p } \\
\$ 4,151^{*}\end{array}$ & \\
\hline $\begin{array}{c}\text { Mio-Tech P550 } \\
\$ 289-\$ 339^{*}\end{array}$ & & $\begin{array}{c}\text { Trimble } 332 \\
\$ 3,000^{*}\end{array}$ & \\
\hline \multicolumn{4}{|l|}{$\begin{array}{c}\text { AgLeader GPS } 1100 \\
\$ 895^{*}\end{array}$} \\
\hline $\begin{array}{c}\text { Raven Invicta } 100 \\
\$ 645^{\star}\end{array}$ & & & \\
\hline
\end{tabular}

